\title{
Conectivivências: (im)possibilidades no contexto pandêmico e no que está por vir ${ }^{1}$
}

\author{
Conectivivencias: (im) posibilidades en el contexto de la pandemia y en el \\ tiempo adelante
}

Connectivities: (im) possibilities in the pandemic context and in the future

\author{
Alessandra Fontes Carvalho da Rocha ${ }^{2}$ \\ Washington Kuklinski Pereira ${ }^{3}$
}

\begin{abstract}
Resumo
O ano de 2020 foi totalmente atípico na educação e na convivência social no Brasil e no mundo. Transformações profundas na vivência da humanidade em meio à necessidade de isolamento social foi um grande desafio para o desenvolvimento educacional em todo o planeta nesse período. Plataformas digitais, redes sociais e diversos meios de atividades remotas passaram a fazer parte da realidade das tentativas de interações entre estudantes e professores. Por isso, nesse trabalho temos como objetivo discutir as possibilidades e impossibilidades no contexto da educação pública na cidade do Rio de Janeiro durante a Pandemia do COVID-19. Para tanto, iremos refletir sobre algumas ações adotadas pela Secretaria Estadual de Educação (SEEDUC) e pela Secretaria Municipal de Educação (SME) bem como a dificuldade de acesso aos meios disponibilizados por parte de estudantes e professores.
\end{abstract}

Palavras-Chave: Educação Pública, COVID-19, Pandemia, Ensino.

\section{Resumen}

El año 2020 fue totalmente atípico en la educación y en la convivencia social en Brasil y en el mundo. Los profundos cambios en la experiencia de la humanidad en medio de la necesidad de aislamiento social fue un gran desafío para el desarrollo educativo en todo el planeta en este período. Las plataformas digitales, las redes sociales y diversos medios de actividades remotas se han convertido en parte de la realidad de los intentos de interacción entre estudiantes y docentes. Por lo tanto, en este trabajo nuestro objetivo es discutir las posibilidades e imposibilidades en el contexto de la educación pública en la ciudad de Río de Janeiro en medio de la realidad de la pandemia del COVID-19. Con este fin, debatiremos las acciones tomadas por la Secretaría de Educación del Estado (SEEDUC) y la Secretaría de Educación de la Municipalidad (SME), así como la dificultad de acceso a los medios puestos a disposición por estudiantes y maestros.

Palabras claves: Educación pública, COVID-19, Pandemia, Docencia.

\begin{abstract}
The year of 2020 was totally atypical for education and social coexistence in Brazil and in the world. Deep changes in the experience of humanity amid the need for social isolation was a major challenge for educational development across the planet in this period. Digital platforms, social networks and various means of remote

\footnotetext{
${ }^{1}$ Artigo apresentado no I Congresso Internacional Online de Estudos sobre Culturas, na modalidade online, 2019.

${ }^{2}$ Doutora em Estudos de Literatura; Universidade Federal do Rio de Janeiro - UFRJ; Rio de Janeiro, Rio de Janeiro, Brasil; profa.alessandra.fontes@gmail.com.

${ }^{3}$ Doutor em História; Fundação de Estudos do Mar - FEMAR/ Secretaria Municipal de Educação do Rio de Janeiro - SME-RJ; Rio de Janeiro, Rio de Janeiro, Brasil; washington.kpereira@rioeduca.net
} 
activities have become part of the reality of attempts at interactions between students and teachers. Therefore, in this work we aim to discuss the possibilities and impossibilities in the context of public education in the city of Rio de Janeiro amid the reality of the COVID-19's Pandemic. To this end, we will debate the actions taken by the State Education Secretariat (SEEDUC) and the Municipal Education Secretariat (SME) as well as the difficulty of access to the means made available by students and teachers.

Keywords: Public Education, COVID-19, Pandemia, Teaching.

\section{Supervivências durante o contexto pandêmico no Brasil}

O cólera se encarniçou muito mais contra a população negra, por ser a mais numerosa e pobre, mas na realidade não teve contemplação com cores nem linhagens. Parou de chofre como havia começado, e nunca se soube o número de suas vítimas, não porque fosse impossível estabelecê-lo, e sim porque uma de nossas virtudes corriqueiras era o pudor das próprias desgraças. (MARQUES, 1986 p.86)

Computadores; celulares; notebooks; tablets; câmera e áudio dos dispositivos; com fone ou sem fone de ouvido; plataformas: Zoom Meeting, Google Meet, Cisco Webex, Microsoft Teams; aparatos tecnológicos e plataformas digitais que passaram a fazer parte da vida pessoal e profissional de alguns brasileiros em março de 2020. Tudo isso provocado pelo cenário que se instalou mundialmente pela pandemia do COVID-194.

Locais e atividades que provocavam aglomerações de pessoas precisaram fechar portas e serem suspensas. Igrejas, famílias e escolas - todas elas instituições sociais passaram a agir a partir de uma outra e inédita dinâmica para o século XXI: o isolamento social. Shoppings, comércios e estabelecimentos com venda de itens e serviços considerados não essenciais também pararam de funcionar no período pandêmico.

Os dois primeiros parágrafos apresentam fragmentos do que vivenciamos no Brasil em 2020. Como já dito anteriomente, o mundo inteiro passou pela mesma pandemia, mas em diversos contextos e com diferentes tomadas de ações de seus gestores políticos. Nossso foco será no Brasil, mais especificamente no município do Rio de Janeiro, localizado no Estado do Rio de Janeiro.

Em 16 de março de 2020, moradores da cidade maravilhosa começaram a viver em quarentena. $\mathrm{O}$ vírus já estava causando estragos em terras brasileiras há algum tempo. Mas,

\footnotetext{
${ }^{4}$ Doença causada por uma mutação do Corona Vírus. Mais informações vide: $<$ https://www.paho.org/bra/index.php?option=com content\&view=article\&id=6101: covid19\&/temid=875>
} 
essa foi a data escolhida por nosso governante para tudo parar, a fim de que a situação não ficasse pior. Começamos a experimentar o que é ficar vinte e quatros horas isolados de tudo e de todos (dentro do possível). No lugar de abraços e beijos, experimentamos os cumprimentos com cotovelos e pés; máscaras e álcool em gel (ou álcool $70^{\circ}$ ) viraram itens essenciais ao sair de casa; no lugar da cerveja com os amigos no bar, apareceram os aplicativos de entrega e até um tal de Zé Delivery que tentou substituir o que é insubstituível (a rodada de "cerva"5 estupidamente gelada com a galera); e, nessa infinidade de gestos e atividades insubstituíveis, a escola também entra em cena.

\section{Conectividades e Vivências: Do COVID-19 à pandemia na educação para todos}

Com as aulas suspensas, como fazer para ter professores, estudantes, salas de aula, conteúdos, hora do recreio, merenda, conversa no pátio escolar? Itens, para nós professores, considerados insubstituíveis. No entanto, voltamos aos aparatos tecnológicos e plataformas digitais para uma adaptação e tentativa de levar a escola até a residência de cada indivíduo.

Mais uma enxurrada de termos pertencentes ao mundo virtual começou a ganhar destaque (e não apenas no cenário escolar): Ensino a distância (EaD); ensino remoto; aulas ao vivo no Youtube; e-mail; whatsapp; lives; Facebook; tudo que pudesse "recriar" o cenário educacional foi utilizado. Oficial e legalmente, escolas e universidades particulares adaptaram o calendário acadêmico com o ensino a distância e atividades remotas. Professores com menos afinidade com as "máquinas" tiveram que correr contra o tempo e se atualizaram para gravarem aulas ou entrarem em plataformas para aulas ao vivo nos mesmos dias e horários das aulas presenciais. Ter câmera e áudio funcionando em computadores, notebooks e celulares passou a ser essencial junto a itens farmacêuticos e alimentícios na vida dos docentes.

De outro lado (o que não deveria soar como dicotômico), escolas e universidades públicas com aulas suspensas e as orientações aos docentes para a realização apenas de atividades de acolhimento, manutenção de vínculo/contato e construção de pertencimento dos estudantes. Quaisquer atividades de natureza obrigatória, avaliativas ou que pudessem substituir o conteúdo programático das disciplinas estavam suspensas. Tal suspensão se justifica pela importância de não ferir o tratamento isonômico que deve ser dado aos

\footnotetext{
${ }^{5}$ Gíria utilizada para designar cerveja
} 
estudantes, cujas condições para acompanhamento e realização de atividades por meios digitais são muito diversas e, em muitos casos, impossível.

$\mathrm{Na}$ educação pública, as escolas estaduais do Rio de Janeiro foram as que receberem orientação diferenciada até o momento ${ }^{6}$. O secretário de educação do Estado do Rio de Janeiro, Pedro Fernandes, implantou o ensino a distância via o Laboratório de Ensino a Distância (LabEad) e a plataforma utilizada é a Google Classroom, da empresa Google For Education. Assim, a Secretaria de Educação do Estado do Rio de Janeiro (SEEDUC) passa a ser SEEDUC Digital. E tal opção não é pela moda da vez, como os termos "digital", "remoto" e “a/à distância". Mas, por uma busca pela adaptação, substituição, recriação, produtividade e movido mais ainda pelo que vem a seguir.

Em meio ao contexto pandêmico, o presidente da República Federativa do Brasil, Jair Messias Bolsonaro, lançou a campanha publicitária com o slogan “o Brasil não pode parar”. Nessa lógica, o fechamento das escolas era questionado e a volta à normalidade deveria ser retomada em nosso país. O clamor presidencial pelo retorno à normalidade se fez em meio aos primeiros $2.915^{7}$ casos confirmados de contaminados pelo COVID-19 e 77 mortes de pessoas que testaram positivo para o vírus.

Vivemos momentos de banalização da morte e, na área da educação, uma das preocupações é o cumprimento da carga horária mínima prevista na Lei de Diretrizes e Bases da Educação Nacional (LDB), como pode ser observado em um dos documentos oficiais, o Parecer CNE/CEP 05/2020 ${ }^{8}$, item 2.2 Da competência para gestão do calendário escolar, e na Medida Provisória ${ }^{\circ} 934$, de $2020^{9}$, quando informa que:

\begin{abstract}
"Dispensa, em caráter excepcional, as escolas de educação básica da obrigatoriedade de observar o mínimo de 200 dias letivos de efetivo trabalho escolar. Determina que a carga horária mínima de oitocentas horas deve ser cumprida, nos termos das normas a serem editadas pelos respectivos sistemas de ensino."10
\end{abstract}

\footnotetext{
${ }^{6}$ Referência temporal ao mês de maio de 2020.

${ }^{7}$ https://www.saude.gov.br/noticias/agencia-saude/46610-brasil-registra-2-915-casos-confirmados-decoronavirus-e-77-mortes

${ }^{8}$ http://portal.mec.gov.br/index.php?option=com docman\&view=download\&alias=145011-pcp00520\&category slug=marco-2020-pdf\&/temid $=30192$

${ }^{9}$ https://www.congressonacional.leg.br/materias/medidas-provisorias/-/mpv/141349

${ }^{10} \underline{\text { https://www.congressonacional.leg.br/materias/medidas-provisorias/-/mpv/141349 }}$
} 
Ainda para a Educação Básica, mais especificamente para o Ensino Fundamental, o Parecer CNE/CEP 05/2020, no item 2.9 Sobre o Ensino Fundamental - Anos Finais e Ensino

Médio, informa:

Nestas etapas, as dificuldades cognitivas para a realização de atividades on-line, são reduzidas ao longo do tempo com maior autonomia dos estudantes, sendo que a supervisão de adultos pode ser feita por meio de orientações e acompanhamentos com o apoio de planejamentos, metas, horários de estudo presencial ou virtualmente. (p. 12)

O parecer observa as dificuldades cognitivas e indica que:

Ao deliberar sobre a possibilidade de realização de atividades pedagógicas não presenciais, para fins de cumprimento de carga horária mínima exigida por lei e reduzir a necessidade de realização de reposição presencial, o sistema de ensino deve observar:

[...]

2. previsão de formas de garantia de atendimento dos objetivos de aprendizagem para estudantes e/ou instituição de ensino que tenham dificuldades de realização de atividades pedagógicas não presenciais; (p. 22-23)

Apesar de prever dificuldades de realização de atividades pedagógicas não presenciais por parte de estudantes e/ou instituições de ensino, as únicas possibilidades de atividades que o documento sugere têm bem recorrente os termos on-line, plataformas digitais e mídias sociais, conforme observamos no trecho abaixo:

Aqui as possibilidades de atividades pedagógicas não presenciais ganham maior espaço. Neste sentido, sugere-se:

- elaboração de sequências didáticas construídas em consonância com as habilidades e competências preconizadas por cada área de conhecimento na BNCC;

- utilização, quando possível, de horários de TV aberta com programas educativos para adolescentes e jovens;

- distribuição de vídeos educativos, de curta duração, por meio de plataformas digitais, mas sem a necessidade de conexão simultânea, seguidos de atividades a serem realizadas com a supervisão dos pais;

- realização de atividades on-line síncronas de acordo com a disponibilidade tecnológica;

- oferta de atividades on-line assíncronas de acordo com a disponibilidade tecnológica;

- estudos dirigidos, pesquisas, projetos, entrevistas, experiências, simulações e outros;

- realização de testes on-line ou por meio de material impresso, entregues ao final do período de suspensão das aulas; e

- utilização de mídias sociais de longo alcance (WhatsApp, Facebook, Instagram etc.) para estimular e orientar os estudos, desde que observadas as idades mínimas para o uso de cada uma dessas redes sociais. (p. 12) 
Queremos ressaltar, aqui, que nossa reflexão neste artigo não gira em torno de críticas relacionadas ao uso de novas tecnologias no campo da educação e nem se reduz a tal. Esta escrita faz parte de um projeto de pesquisa intitulado Conectivivências: (im)possibilidades educacionais no contexto pandêmico e no pós-pandemia que tem como interesse maior o campo educacional e objetiva usar a história e a literatura para "olhar para trás" e perceber como a sociedade enfrentou outros momentos de pandemia e guerra. Somamos a isso o grande interesse do projeto de pesquisa que é investigar como o processo educativo nas escolas públicas do município do Rio de Janeiro e seus sujeitos são afetados pelas políticas públicas educacionais criadas em razão da pandemia de COVID-19, sendo políticas que legitimam práticas pedagógicas ligadas ao ensino remoto e a aulas online, que, pelas características sociais da cidade, aprofundam as desigualdades, observando de que maneira é possível a ocupação de novos espaços (inclusive virtualmente) e a utilização dos meios de conectividade para romper a estrutura opressora na educação.

Por isso, neste artigo, apresentamos o momento inicial da pesquisa que teve como eixo central as leituras e as discussões dos documentos oficiais ${ }^{11}$ aprovados durante o período de pandemia e que norteiam as práticas educacionais em um país extremamente excludente e segregador. Problemas estes reconhecidos no próprio documento criado para "Reorganização do Calendário Escolar e da possibilidade de cômputo de atividades não presenciais para fins de cumprimento da carga horária mínima anual, em razão da Pandemia da COVID-19.”:

[...] é importante considerar as fragilidades e desigualdades estruturais da sociedade brasileira que agravam o cenário decorrente da pandemia em nosso país, em particular na educação, se observarmos as diferenças de proficiência, alfabetização e taxa líquida de matrícula relacionados a fatores socioeconômicos e étnico-raciais. Também, como parte desta desigualdade estrutural, cabe registrar as diferenças existentes em relação às condições de acesso ao mundo digital por parte dos estudantes e de suas famílias. Além disso, é relevante observar as consequências socioeconômicas que resultarão dos impactos da COVID19 na economia como, por exemplo, aumento da taxa de desemprego e redução da renda familiar. Todos estes aspectos demandam um olhar cuidadoso para as propostas de garantia dos direitos e objetivos de aprendizagem neste momento a fim de minimizar os impactos da pandemia na educação. Tal situação leva a um desafio significativo para todas as instituições ou redes de ensino de educação básica e ensino superior do Brasil, em particular quanto à forma como o calendário escolar deverá ser reorganizado. É necessário considerar propostas que não aumentem a desigualdade ao mesmo tempo em que utilizem a oportunidade trazida por novas tecnologias digitais de informação e comunicação para criar formas de diminuição das desigualdades de aprendizado. (p. 3 - Grifos nossos)

\footnotetext{
${ }^{11}$ Referência a documentos oficiais aprovados e homologados até maio de 2020, período de elaboração deste artigo.
} 
Como considerar propostas que não aumentem a desigualdade e, ao mesmo tempo, utilizar a "oportunidade" trazida por novas tecnologiais digitais de informação e comunicação? A resposta não está posta no parecer! E o mesmo ainda traz muitos outros questionamentos em formato de desafios a serem enfrentados no contexto pandêmico, como por exemplo:

Como reorganizar os calendários escolares, considerando as condições particulares de cada rede, escola, professores, estudantes e suas famílias? Dentre os desafios a serem enfrentados, destacam-se:

- como garantir padrões básicos de qualidade para evitar o crescimento da desigualdade educacional no Brasil?

- como garantir o atendimento das competências e dos objetivos de aprendizagens previstos na Base Nacional Comum Curricular (BNCC) e nos currículos escolares ao longo deste ano letivo?

- como garantir padrões de qualidade essenciais a todos os estudantes submetidos a regimes especiais de ensino que compreendam atividades não presenciais mediadas ou não por tecnologias digitais de informação e comunicação? • como mobilizar professores e dirigentes dentro das escolas para o ordenamento de atividades pedagógicas remotas? (p. 4)

A preocupação colocada pelo parecer do Conselho Nacional de Educação é o não aumento da desigualdade que já está reconhecida no mesmo documento como as "diferenças existentes em relação às condições de acesso ao mundo digital por parte dos estudantes e de suas famílias.”(p. 3) e como "solução" temos a seguinte afirmação: “As soluções possíveis dependerão das decisões de reorganização dos calendários escolares dos sistemas de ensino e da adequada preparação dos professores." (p. 4). O documento também apresenta algumas possibilidades de cumprimento da carga horária mínima estabelecida pela LDB. No entanto, o mesmo texto se faz esquecido sobre o que apresenta em páginas anteriores e é o que colocamos no centro de nossa discussão neste artigo.

Como fazer para usar as novas tecnologiais no campo educacional de um país cheio de desigualdades e que tal uso não aumente ainda mais essa desigualdade? Esse é um questionamento feito na perspectiva do próprio parecer e que na nossa visão e urgência da situação deve ser reestruturado da seguinte forma: Em um momento de calamidade pública declarada; de suspensão de aulas e de outras atividades a partir do isolamento social, como repensar a educação de forma a mantê-la para todos, aproveitando para tomada de ações que contribuam para atenuar e até mesmo acabar com desigualdades presentes na sociedade? Veremos, mais adiante, que tais questões não são necessárias apenas hoje e em tempo de pandemia e que se colocam, na prática, há uma década, período que analisaremos um projeto de inclusão de plataformas digitais no ensino público do município do Rio de Janeiro. 
Sem previsão de vacina e tratamento comprovado cientificamente; hospitais com poucos leitos e pouquíssimos respiradores; poucos recursos para testagem para diagnosticar o vírus em toda a população; projeção de um grande aumento dos números de infectados e mortos pelo vírus em pequeno espaço de tempo; dentre todos os outros problemas (políticos, econômicos e sociais) que assolam o Brasil, como pensar em retorno à normalidade e que conceito de normal / novo normal é esse? Antes da pandemia ocasionada por um vírus, vivíamos uma normalidade? Como pensar em cumprimento de carga horária mínima e atividades não presenciais realizadas remotamente, se vivemos em um país que, antes do momento pandêmico, 54,8 milhões de brasileiros já viviam abaixo da linha da pobreza, o que significa viver com uma renda inferior a $\mathrm{R} \$ 406,00$ por mês ${ }^{12}$ ? E que se ainda fosse um único brasileiro entre toda a população do país sem acesso a qualquer possibilidade de educação, inclusive de forma remota, isso já caracterizaria a infração do Art. $3^{\circ}$ da LDB que afirma que "O ensino será ministrado com base nos seguintes princípios: I - igualdade de condições para o acesso e permanência na escola;" e do Art. $6^{\circ}$ da Constituição Federal de 1988: "São direitos sociais a educação, a saúde, a alimentação, o trabalho, a moradia, o transporte, o lazer, a segurança, a previdência social, a proteção à maternidade e à infância, a assistência aos desamparados, na forma desta Constituição.”. E quem tem a responsabilidade de proporcionar o acesso à educação? De acordo com a própria Constituição, no Inciso $\mathrm{V}$ do Artigo 23, é competência comum a União, aos Estados, Nunicípios e ao Distrito Federal "proporcionar os meios de acesso à cultura, à educação e à ciência".

Por isso, caro leitor, insistimos no âmbito educacional e continuaremos no contexto pandêmico em meio a discussões calorosas sobre a substituição de aulas presenciais por EaD ou ensino remoto ou ensino remoto emergencial, principalmente nas escolas públicas. Segundo dados do Instituto Brasileiro de Geografia e Estatística (IBGE) em pesquisa ${ }^{13}$ realizada sobre o uso da "Tecnologia da Informação e Comunicação - TIC" no Brasil em 2017, 74,9\% dos domicílios brasileiros têm acesso à internet para uso pessoal. Nas residências onde não havia utilização da internet, os pesquisados declararam alguns motivos para não usála, sendo os três principais: i) falta de interesse em acessar a Internet $(34,9 \%)$; ii) o serviço de acesso à Internet era caro (28,7\%); e iii) nenhum morador sabia usar a Internet (22,0\%). Já em áreas rurais, se destacou a indisponibilidade do serviço de internet em 21,3\% dos domicílios.

\footnotetext{
${ }^{12}$ https://jornal.usp.br/atualidades/brasil-tem-55-milhoes-de-pessoas-abaixo-da-linha-da-pobreza/

${ }^{13}$ https://educa.ibge.gov.br/jovens/materias-especiais/20787-uso-de-internet-televisao-e-celular-nobrasil.html
} 
Diante dos dados, mais uma questão se faz urgente: como pensar em $\mathrm{EaD}$ ou ensino remoto, mesmo emergencial (termos distintos, mas ambos cogitados no momento de isolomento social que já passou de 60 dias), em período de pandemia para substituir a educação pública e de qualidade para todos em uma sociedade democrática?

Essa é uma pergunta que nos fazemos hoje junto com tantos outros sentimentos que experimentamos e que são provocados por um vírus imperceptível aos nossos olhos e que nos faz temer o que está por vir. No entanto, também não enxergamos o que já estava posto em nossa frente e que, de forma escancarada, é legitimado no campo da educação. A seguir, nossos leitores não encontrarão reflexões sobre o hoje e o que está por vir. Mas, apresentaremos como as novas tecnologias já participavam de forma discreta da educação pública, mesmo não existindo em nossa sociedade igualdade de acesso para todos.

Aproximadamente uma década antes do momento pandêmico, uma reestruturação da Secretaria Municipal de Educação do Rio de Janeiro proporcionou a iniciativa da Subsecretaria de Projetos Estratégicos criar a iniciativa que permitiu aos estudantes e professores acesso à plataforma online Educopédia ${ }^{14}$.

O objetivo da política pública de educação, naquele momento, não era apenas direcionar os docentes para a preparação dos estudantes na execução das provas bimestrais e, consequentemente, para a Prova Rio ${ }^{15}$, mesmo sendo um sistema organizado por disciplina, ano de escolaridade e tema do conteúdo programático proposto pela prefeitura a partir das orientações do currículo mínimo obrigatório. Era um primeiro passo no estabelecimento da criação de uma cultura de educação digital para os estudantes e professores naquele momento. Para tanto, professores ganharam computadores, escolas foram equipadas com projetores e sistemas de áudio e salas de aula receberam cabeamento de internet em todas as escolas, com pacote de dados de aproximadamente $2 \mathrm{Mb}$ e, no ano de 2018, através do Programa Dinheiro Direto na Escola - Escola Conectada (PDDE Escola Conectada), viabilizado pelo Governo Federal, foi disponibilizado para as escolas do município do Rio de Janeiro a atualização do sistema de conectividade e o custeio para contratação de banda de internet de alta velocidade.

O projeto PDDE Escola Conectada foi grandioso, pois a realidade do município do Rio de Janeiro é de volumosa heterogeneidade. A cidade conta com uma das maiores redes

\footnotetext{
${ }^{14}$ http://www.educopedia.com.br/

${ }^{15}$ Sistema de exame criado pela Secretaria Municipal de Educação do Rio de Janeiro (SME-RJ) e aplicado aos estudantes do ensino fundamental com o objetivo de mensurar o ensino e estabelecer metas para os anos escolares seguintes.
} 
públicas de ensino da América Latina, sendo 1.537 unidades escolares; 651.655 alunos matriculados; 41.302 docentes; 15.191 funcionários de apoio e administrativos ${ }^{16}$, distribuídos em uma cidade com aproximadamente 6,5 milhões de habitantes, distribuídos em 5265,82 $\mathrm{km}^{217}$

Para muitas escolas públicas da cidade do Rio de Janeiro, bastava apenas que o professor ou o estudante, utilizando da estrutura fornecida pela própria rede, se conectasse a plataformas diversas durante a aula ou em casa para acessar os materiais. Vídeos e músicas em streeming e tudo mais que os professores pudessem acessar ou recomendar acesso poderia estar a poucos cliques da realidade da sala de aula. Ainda era possível ampliar a utilização da plataforma Educopédia, pois os professores de todas as disciplinas poderiam acessar um banco de dados onde teriam planos de aula, exercícios, atividades e apresentações de aulas já prontas em slides. Todo o material disponibilizado na plataforma foi produzido por professores do município e para professores do município.

As possibilidades da ferramenta são inúmeras. Na página inicial, ao fazer o login como professor da rede ou como visitante, o usuário do sistema acessa uma área onde tem a opção de escolher o ano escolar sobre o qual pretende buscar as informações, escolher dentro do quadro de disciplinas oferecidas como eletivas ou obrigatórias e ainda eleger uma das oito propostas bimestrais da disciplina de interesse, podendo assim fazer o download de planos de aula e de apresentações em slides disponibilizados na plataforma.

Ainda uma década antes do momento pandêmico, durante a implantação da Educopédia como suporte para o acesso à plataforma e para futuras ações de conectividade entre estudantes e professores, a Secretaria Municipal de Educação do Rio de Janeiro ainda criou um e-mail institucional para todos os funcionários e estudantes em parceria com a Microsoft, proporcionando também acesso às plataformas digitais da empresa estadunidense, como Forms, Class Notebook e, atualmente, a plataforma Teams.

Entretanto, em meio ao isolamento social causado pela pandemia que se iniciara em março de 2020, todas as plataformas obtidas pela Prefeitura do Rio de Janeiro foram a princípio deixadas de lado e como forma de manutenção de vínculo com discente foi incentivado o uso de redes sociais como Facebook e Instagran. O que já era subutilizado passou a parecer não existir em um período de excepcionalidade. Qual seria o objetivo da gestão municipal em não utilizar os meios que já tinham, mas, sim, apostar em redes sociais

\footnotetext{
${ }^{16}$ http://prefeitura.rio/web/smeel/educacao-em-numeros

${ }^{17}$ Dados disponíveis em: http://cidades.ibge.gov.br/xtras/perfil.php?codmun=330455
} 
que expõe as ações dos servidores da educação para manter os vínculos com os estudantes ao invés de aproveitar os canais dessas diferentes redes para promover as plataformas já existentes na rede municipal de ensino? Por que somente após 60 dias de isolamento social foi proposta a utilização da plataforma Teams como meio para manutenção de vículo com estudantes por parte da Secretaria Municipal de Educação? Por que até o momento não houve divulgação, tampouco incentivo para o uso da plataforma Educopédia?

Sabemos que todas essas questões têm respostas que ultrapassam o campo educacional e alcançam dimensões relacionadas a estratégias políticas, parcerias com grandes empresas privadas, interesses difusos, ruptura com projetos iniciados em gestões anteriores, principalmente no decorrer de um ano eleitoral.

O que poderia ser umas das primeiras iniciativas para atenuar o problema de acesso não ocorreu até o momento. Não houve a distribuição, por parte do Estado ou do Município, de chips de internet para o uso de rede móvel para estudantes e professores. Por mais que possamos pensar que em uma cidade tão grande há diversos locais onde a rede de telefonia móvel não tem cobertura, isso não se aplica ao município do Rio de Janeiro, pois, em virtude de contrato para fornecimento de telecomunicações para as Olimpíadas Rio 2016, a empresa Grupo América Móvel foi obrigada a ampliar a rede de comunicação, aumentando a cobertura da subsidiária de serviços móveis, Claro Telecom, para toda a cidade como parte do legado olímpico $^{18}$, o que possibilitaria, no atual momento, maior ampliação do acesso.

Essa é apenas uma micro iniciativa dentre outras questões mais complexas que se colocam em meio à imposição da urgência de produtividade e da volta à possível normalidade ou ao "novo normal" de maneira desenfreada que o atual Presidente da República tem defendido durante a pandemia vivida por nós, mas que para o líder na gestão do Brasil é apenas uma "gripezinha"19.

Não podemos ignorar que a própria gestão do Brasil, o vírus do momento e todos os direcionamentos dados à população brasileira dos diferentes ministérios, principalmente da Saúde, Educação e Economia, são desafios enfrentados por parte da população. Junto a essas principais adversidades, estudantes e professores lidam com o problema de acesso à internet e a falta de recursos materiais para conectividade a plataformas e outras redes virtuais, o que

\footnotetext{
${ }^{18}$ https://agenciabrasil.ebc.com.br/geral/noticia/2016-06/infraestrutura-de-telecomunicacoes-para-jogosolimpicos-e-apresentada-no-rio

${ }^{19}$ Referência ao pronunciamento do Presidente da República Federativa do Brasil, Jair Messias Bolsonaro, no dia 24 de março de 2020, às 20h30. Disponível em: https://noticias.uol.com.br/politica/ultimasnoticias/2020/03/24/leia-o-pronunciamento-do-presidente-jair-bolsonaro-na-integra.htm
} 
também não é um problema novo. Esses dois últimos também são o que consideramos como os dois maiores problemas atuais para o cumprimento do que o Parecer CNE/CEP 05/2020 define como principal finalidade do processo educativo:

o atendimento dos direitos e objetivos de aprendizagem previstos para cada etapa educacional que estão expressos por meio das competências previstas na BNCC e desdobradas nos currículos e propostas pedagógicas da instituições ou redes de ensino de educação básica ou pelas Diretrizes Curriculares Nacionais e currículos dos cursos das instituições de educação superior e de educação profissional e tecnológica (p. 4)

Se os conteúdos curriculares são apresentados em plataformas ou redes sociais que exigem o acesso, por parte de estudantes e professores, além dos gestores escolares, à internet para efetivo ensino remoto, não há garantia mínima de desenvolvimento de qualquer habilidade ou competência prevista em documentos oficiais, como a BNCC e/ou outros. Ainda sobre esse aspecto, voltamos a um ponto importante que tanto aparece no ensino presencial quanto no ensino remoto: a turma e cada estudante que compõe essa turma.

O coletivo e o individual andam muito próximos no ambiente escolar e em todas as análises que são feitas no campo educacional, como por exemplo nos famosos Conselhos de Classe. Durante esse tipo de reunião, professores e gestores escolares sempre focam os olhares para a parte de um todo: a turma Y e o estudante A da turma Y. Essa visão do todo e de partes que formam o todo mostra bem que o individual importa e que não é apenas um número, como o número 1 (um) da lista de presença. É um alguém com nome; determinada identidade; feliz ou infeliz, dependendo do momento; com ou sem estrutura familiar; mora em um determinado bairro; com ou sem infraestrutura; com uma determinada renda familiar; com muitos ou pouquíssimos recursos; com ou sem acesso à internet; com uma história de vida; e com muitas outras características que irão lhe definir como um sujeito singular e que irão apontar ao sistema educacional se ficará para trás ou não ao adotarmos determinadas formas de ensino, independente de ser presencial ou a distância. O mesmo vale para os docentes.

Por isso, nossa resistência é no sentido de nenhum a menos ${ }^{20}$, o que exige de nossos governantes não apenas o reconhecimento da desisgualdade no Brasil e propostas para reorganização do calendário escolar, mas, primeiramente e prioriateriamente, ações ativas na democratização do acesso a todo e qualquer tipo de material, principalmente digital, de uso obrigatório ou complementar, que seja implantado nas escolas públicas brasileiras.

\footnotetext{
${ }^{20}$ Referência ao filme Nenhum a Menos. Direção: Zhang Yimou. China, 1999, 106 minutos. Elenco: Wei Minzhi, Zhang Huike, Tian Zhenda, Gao Enman, Sun Zhimei.
} 
Enquanto aguardamos a tomada de decisão por parte dos nossos governantes, o que inclui, inclusive, ações contra a fome e o desemprego em nosso país, essa pesquisa segue vivendo o problema pesquisado, o que faz dela uma proposta mutável, dinâmica e incompleta para o momento. Essas três caracterísitcas nos fazem compreender a impossibilidade deste artigo apresentar uma conclusão, pois entendemos que ainda estamos bem longe dela. Mas, temos como encaminhamento final as palavras de Nelson Rodrigues, quando o mesmo escreveu a crônica A menina sem estrela: Memórias: "A espanhola trouxera no ventre costumes jamais sonhados. E, então, o sujeito passou a fazer coisas, a pensar coisas, a sentir coisas inéditas [...]" (p. 57)

É nesse ato do sujeito passar a fazer, pensar e sentir "coisas" que concentramos nossos esforços em uma tentativa de tomada de decisão por parte da população por um viés que é o de transgredir o projeto de país que está posto, de forma a romper a estrutura desigual, opressora e colonial que ainda temos. Lembremos do que foi a Primavera Árabe e o quanto as redes sociais foram recursos propagadores do movimento. Analisemos a importância dos comunicadores de favelas, por exemplo, e teremos a certeza de que as possíveis formas de conectividade vinculadas a diferentes vivências podem gerar formas concretas de ocupação de novos espaços (inclusive espaços virtuais, como: redes sociais, plataformas e outros) por parte da população para a luta contra a desigualdade, exclusão social e as consequências dessa ocupação no contexto educacional, principalmente na ruptura com a colonialidade na educação. Acreditamos que a mudança pode acontecer por parte da população e compreendemos que a potencialização desse movimento é possível com as pesquisas na área das Ciências Humanas e a democratização de acesso a esses saberes.

\section{Referências}

BRASIL. Lei de Diretrizes e Bases da Educação Nacional. Lei número 9394, 20 de dezembro de 1996.

Constituição da República Federativa do Brasil. Brasília, DF: Senado Federal: Centro Gráfico, 1988.

MARQUES, Gabriel García. O amor nos tempos de cólera. Rio de Janeiro: Record, 1986. Portal da Educopédia. Disponível em: http://www.educopedia.com.br/ Acesso em: $01 / 04 / 2017$

Portal do Instituto Brasileiro de Geografia e Estatística. Disponível em: http://cidades.ibge.gov.br/xtras/perfil.php?codmun=330455 Acesso em: 01/04/2020 
Portal da Prefeitura do Rio de Janeiro. Disponível em:

http://prefeitura.rio/web/smeel/educacao-em-numeros Acesso em: 01/04/2020

Portal do Ministério da Saúde: https://www.saude.gov.br/noticias/agencia-saude/46610-brasilregistra-2-915-casos-confirmados-de-coronavirus-e-77-mortes Acesso em 25/05/2020

Portal do Ministério da Educação:

http://portal.mec.gov.br/index.php?option=com_docman\&view=download\&alias=145011pcp005-20\&category_slug=marco-2020-pdf\&Itemid=30192 Acesso em 30/05/2020.

Portal do Congresso Nacional: https://www.congressonacional.leg.br/materias/medidasprovisorias/-/mpv/141349 Acesso em 30/05/2020

Portal Jornal da USP: https://jornal.usp.br/atualidades/brasil-tem-55-milhoes-de-pessoasabaixo-da-linha-da-pobreza/ Acesso em 30/05/2020

Portal do IBGE: https://educa.ibge.gov.br/jovens/materias-especiais/20787-uso-de-internettelevisao-e-celular-no-brasil.html Acesso em 30/05/2020

Portal Educoédia: http://www.educopedia.com.br/ Acesso em 30/05/2020

Portal da Secretaria Municipal de Educação: http://prefeitura.rio/web/smeel/educacao-emnumeros Acesso em 30/05/2020

Portal do IBGE: http://cidades.ibge.gov.br/xtras/perfil.php?codmun=330455 Acesso em $30 / 05 / 2020$

Portal da Agência Brasil EBC: https://agenciabrasil.ebc.com.br/geral/noticia/2016-

06/infraestrutura-de-telecomunicacoes-para-jogos-olimpicos-e-apresentada-no-rio Acesso em $30 / 05 / 2020$

Pronunciamento do Presidente da República Federativa do Brasil, Jair Messias Bolsonaro, no dia 24 de março de 2020, às 20h30. Disponível em:

https://noticias.uol.com.br/politica/ultimas-noticias/2020/03/24/leia-o-pronunciamento-dopresidente-jair-bolsonaro-na-integra.htm Acesso em 30/05/2020.

RODRIGUES, Nelson. A menina sem estrela: Memórias. São Paulo: Companhia das Letras, 1993.

Filme Nenhum a Menos. Direção: Zhang Yimou. China, 1999, 106 minutos. Elenco: Wei Minzhi, Zhang Huike, Tian Zhenda, Gao Enman, Sun Zhimei. 